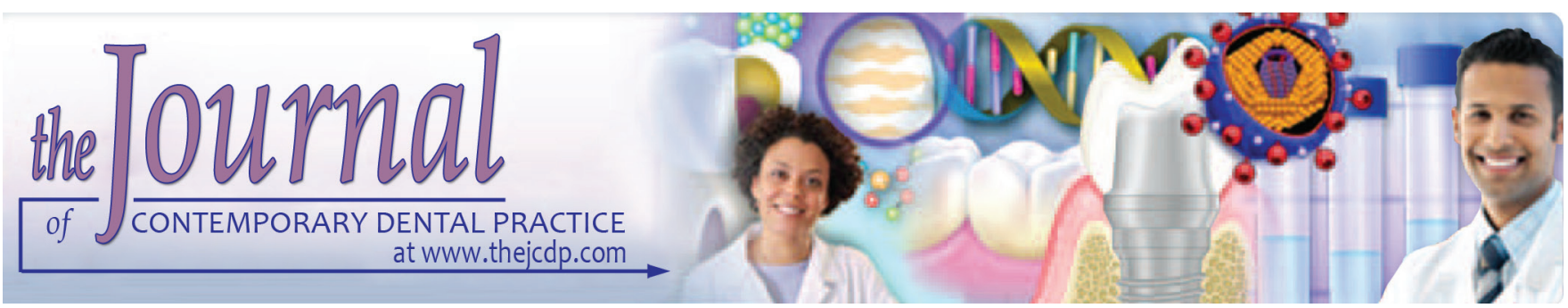

\title{
Impact of the Root Canal Taper on the Apical Adaptability of Sealers used in a Single-cone Technique: A Micro-computed Tomography Study
}

\author{
${ }^{1}$ Sfeir Germain, ${ }^{2}$ Kohli Meetu, ${ }^{3}$ Khalil Issam, ${ }^{4}$ Naaman Alfred, ${ }^{5}$ Zogheib Carla
}

\begin{abstract}
Aim: The purpose of this study was to assess the influence of root canal taper on the apical adaptability of three root canal sealers used in a single-cone technique by measuring void's volume.
\end{abstract}

Materials and methods: Thirty-six maxillary premolar root canals were divided into two groups. Eighteen root canals were shaped with iRace/FKG 0.3 to 0.04 instrument and 18 with 0.3 to 0.06 iRace/FKG instrument. Roots were then scanned using micro-computed tomography (CT). Each group was divided into three subgroups, containing six samples each, filled respectively, with AHPlus $^{\circledR}(A H)$, TotalFill ${ }^{\circledR}(T F)$, and a novel bioceramic (NB) sealers. The roots were rescanned using micro-CT in order to superimpose the two scans and calculate the voids volume in the apical third. Statistical analyses were done using analysis of variance (ANOVA) test with a level of significance $(p<0.05)$.

$\mathrm{AH} 4$ is for the $4 \%$ tapered root canals that are filled with AH sealer. TF4 is for the $4 \%$ tapered root canals that are filled with TF. NB4 is for the $4 \%$ tapered root canals that are filled with the NB sealer.

$\mathrm{AH} 6$ is for the $6 \%$ tapered root canals that are filled with $\mathrm{AH}$. TF6 is for the $6 \%$ tapered root canals that are filled with TF. NB6 is for the $6 \%$ tapered root canals that are filled with the NB sealer.

Results: Regarding void's volume measurements, all groups filled with $\mathrm{AH}$ and TF sealers showed similar results for both tapers with no statistical differences ( $p>0.05) ; 4 \% \mathrm{AH}: 0.0354$ $\pm 0.0354 ; 4 \%$ TF: $0.0370 \pm 0.0245 ; 6 \%$ AH: $0.0447 \pm 0.0348$; $6 \%$ TF: $0.0588 \pm 0.0150(p>0.05)$, whereas $6 \%$ tapered preparations showed significantly less voids compared with

\footnotetext{
1,3-5 Department of Endodontics, Saint Joseph University, Beirut Lebanon

${ }^{2}$ Department of Endodontics, University of Pennsylvania School of Dental Medicine, Philadelphia, Pennsylvania, USA

Corresponding Author: Zogheib Carla, Department of Endodontics, Saint Joseph University, Beirut, Lebanon, e-mail: Zogheibcarla@gmail.com
}

$4 \%$, specifically for the NB sealer tested. $4 \%: 0.123 \pm 0.130$; 6\%: $0.068 \pm 0.035(p<0.05)$.

Conclusion: Bioceramic (BC) sealers showed good all-round performance demonstrating good adaptability, and reduced voids while maintaining similar characteristics when compared with conventional resin sealer.

Clinical significance: The conservative preparations in $\mathrm{AH} 4$ and TF4 did not induce less voids compared with more enlarged tapers (6\%) in AH6 and TF4 groups.

Keywords: Bioceramics, Micro-computed tomography, Sealer, Taper, Voids.

How to cite this article: Germain S, Meetu K, Issam K, Alfred N, Carla Z. Impact of the Root Canal Taper on the Apical Adaptability of Sealers used in a Single-cone Technique: A Micro-computed Tomography Study. J Contemp Dent Pract 2018;19(7):808-815.

\section{Source of support: Nil}

Conflict of interest: None

\section{INTRODUCTION}

Despite the technological leaps in dentistry today, there is no doubt that natural teeth have better esthetical and mechanical properties than all other replacements. Endodontic therapy is a series of interlinked steps that aim to preserve or heal periapical tissues and keep proper tooth function. ${ }^{1,2}$ Enlarging the root canal has an impact on tooth durability, thus leading sometimes to endodontic treatment failure due to an irreversible tooth fracture attributed to dental structural loss. ${ }^{3,4}$ Preserving dentinal tissue might overcome these failures. Conservative approach $^{5,6}$ in endodontics consists in minimal tapered preparations, sufficient apical diameter in treated teeth, and gutta-percha sealer single-cone obturations. Calcium silicate sealers, such as EndoSequence ${ }^{\circledR}$ (Brasseler USA, Savannah, GA) or TF have been lately introduced for this 
objective. ${ }^{7}$ The apical adaptability of these sealers disables bacterial percolation by creating a hydroxyapatite layer with dentinal root canal walls resulting in limited shrinkage and good biocompatibility in favor of endodontic long-term prognosis. ${ }^{8-11}$ However, BC sealers are difficult to remove during retreatments. A study elaborated in 2011 showed that conventional retreatment techniques are unable to totally remove $\mathrm{BC}$ sealers. ${ }^{12}$ In this range, a new BC-based sealer (NB) (St Joseph University, Beirut, Lebanon) composed of tricalcium silicate, dicalcium sulfate, calcium carbonate, tantalum oxide was developed lately. ${ }^{13}$ The powder is obtained by a sol-gel method making it more bioactive than materials prepared by other methods. ${ }^{14}$ The presence of calcium carbonate in this NB sealer helps improve the product removal during retreatment. Its radiopacity and properties are comparable to other sealers used clinically. ${ }^{15}$

The apical adaptability of endodontic obturating materials in minimally apical tapered preparations remains uncertain. In this study, the correlation between conservative approach and the quality of the apical seal was analyzed using micro-CT. Our objective was to compare the influence of the root canal taper on the apical adaptability of three types of sealers used in a single gutta-percha cone-filling technique. The null hypothesis tested was that no difference would be found between all tested sealers for 4 and $6 \%$ more conventional tapered preparation.

\section{MATERIALS AND METHODS}

\section{Specimen Selection and Preparation}

Thirty-six roots of upper first maxillary premolars, freshly extracted, were collected from the Oral Surgery Department of Saint-Joseph University, Beirut. A previous micro-CT scanning has been performed in order to enable anatomical matching among the teeth used, due to the large variety of anatomical configurations of maxillary premolars. Roots with an apical curvature between 15 and $30^{\circ}$, as determined by Schneider's method, were included in the study. Roots presenting internal and external resorptions, fracture, or immature apices were excluded from the study. Preliminary radiographs were taken in buccolingual and mesiodistal directions to verify the absence of endodontic irregularities or root canal treatment. Root surfaces were manually scaled, rinsed under running water, then kept in Formol 10\% for 1 week.

\section{Root Canal Preparation}

Access cavity was performed on all crowns. A \#10 K-flexofile (Dentsply, Maillefer, Switzerland) was introduced. When it reached the apical foramen, working length (WL) was set $1 \mathrm{~mm}$ shorter. After introduction of hand files and establishment of a glide path, teeth were divided into two groups:

Group I: Eighteen root canals were shaped with iRaCe (FKG Dentaire, Switzerland) as follows: (0.1-0.02)$(0.1-0.04)-(0.15-0.04)-(0.2-0.04)$ and $(0.3-0.04)$ in continuous rotation, with a $600 \mathrm{rpm}$ speed and a torque of $2.0 \mathrm{~N}$ using a light apical pressure. After each file, a size \#10 K-file was taken to the WL to check patency and irrigation followed with $1 \mathrm{~mL}$ of $5.25 \% \mathrm{NaOCl}$. The previous sequence was repeated until instruments reached the $\mathrm{WL}$. The final shaping resulted for group I in a $0.3 \mathrm{~mm}$ diameter and a $4 \%$ taper for each root canal.

Group I was divided into three subgroups as follows: AH4 for AH Dentsply, taper 4\%; TF4 for TF, FKG, taper $4 \%$; and NB4 for NB, taper $4 \%$. Each group was composed of six root canals. Every subgroup is named after the sealer that will be applied in the "single-cone obturation" process later on.

Group II: Eighteen root canals were prepared with iRaCe (FKG Dentaire, Switzerland) as follows: (0.1$0.02)-(0.1-0.04)-(0.1-0.06)-(0.2-0.06)-(0.3-0.04)$, and finally (0.3-0.06). The final shaping result for group II was a $0.3 \mathrm{~mm}$ diameter and a $6 \%$ taper for each root canal.

Group II was divided into three subgroups as follows: AH6 (AHPlus Dentsply, taper 6\%), TF6 (TF, FKG, taper $6 \%$ ), and NB6 (novel BC, taper $6 \%$ ).

AH6, TF6, and NB6 contain six root canals each. Every subgroup was named after the sealer that will be applied in the "single-cone obturation" process later on. After finishing the canal shaping, $3 \mathrm{~mL}$ of distilled water was used to remove the remaining sodium hypochlorite. A final flush of $1 \mathrm{~mL} \mathrm{17 \%}$ ethylenediaminetetraacetic acid (EDTA) ( $\mathrm{pH}=7.7$ ) SmearClear (SybronEndo, Orange, California, USA) was applied to eliminate the smear layer. Then, the canals were washed with $3 \mathrm{~mL}$ saline solution and dried with paper points (FKG Dentaire, Switzerland).

\section{First Micro-CT Analysis}

After root canal preparation, specimens scanning was carried out with a high-resolution micro-CT, v $\mid$ tome $\mid x$ 240D (General Electric, Massachusetts, USA) using a $0.60^{\circ}$ rotational step, and a $360^{\circ}$ rotational angle in 0.3 steps randomized movements, with a $13.50 \mu \mathrm{m}$ resolution. This is performed in order to measure the volume of the apical third of every shaped root canal before the filling. Every two teeth were scanned together in approximately 20 minutes.

\section{First Analysis of Images}

The data acquiring and reconstruction were done with the datos $\mid \times 2.0$ software. The first image analysis was processed with the "VG StudioMax 3.0" software, with 
beam hardening and ring artifact correction of $0 \%$. The voxel number for each scanned tooth was a set of data with 900 cross-sections per sample.

\section{Root Canal Filling}

All canals were afterward dried using paper points and randomly assigned to two experimental groups $(n=18)$ according to final preparation taper. Then each group was divided into three subgroups according to the sealer used in a single gutta-percha cone obturation technique. In each group (AH4, AH6, TF4, TF6, NB4, and NB6), a lentulo was used in the dried root canal with the corresponding sealer before inserting the master cone, in order to perform the single-cone technique.

The AH4 subgroup was filled with a 30 to $34 \%$ singletapered gutta-percha cone with $\mathrm{AH}$ (Dentsply) resin sealer, the TF4 subgroup was filled with a 30 to $34 \%$ tapered and coated gutta-percha cone in single-cone filling with TF (FKG Dentaire, Switzerland) sealer, and the NB4 with a 30 to $34 \%$ tapered and coated gutta-percha cone in single-cone filling with an experimental BC sealer. In all groups, the prefitted master cone coated with a thin layer of sealer was inserted into the canal till WL.

The AH6 subgroup was filled with a 30 to $36 \%$ singletapered gutta-percha cone with $\mathrm{AH}$ (Dentsply) resin sealer, the TF6 subgroup with a 30 to $36 \%$ tapered and coated gutta-percha cone in single-cone filling with TF (FKG Dentaire) sealer, and the NB6 subgroup with a 30 to $36 \%$ tapered and coated gutta-percha cone in singlecone filling with an experimental BC sealer. In all groups, the prefitted master cone was coated with a thin layer of sealer on its three apical $\mathrm{mm}$ and inserted into the canal till the WL.

All roots were stored at $37^{\circ} \mathrm{C}$ with $100 \%$ humidity for about 72 hours to allow the sealers to set completely until a second micro-CT scan.

\section{Second Micro-CT Analysis}

Specimens were rescanned (same micro-CT parameters) after obturation for micro-CT analysis in order to measure the filled apical third of every root canal. Pre- and postfilling scans were superimposed for each sample in order to calculate the ratio of remaining voids in the apical third. The initial volume corresponds to the volume after shaping and cleaning. The final volume corresponds to the volume scanned after single-cone filling. Initial and final volumes are superimposed. The VG studio Max 3.0 software was used. The same observer assessed all the analysis.

\section{Voids Calculation}

After preparation, before obturation, specimens were scanned using micro-CT (Fig. 1) in order to measure the root canal's volume. This measurement is performed under a selection called "segmentation" and consists of the initial volume.

After obturation micro-CT rescans were achieved (Fig. 2) in order to measure the filling material's volume. This measurement is performed under the same selection used in the first scan and consists of the final volume. The second scan is imported into the first one and both volumes were aligned regarding the external root surfaces (best-fit).

Voids were determined by subtracting the final volume from the initial one.

\section{Statistical Analysis}

Statistical Package for the Social Sciences (SPSS for Windows, Version 20.0, Chicago, Illinois, USA) software was used to perform the statistical analysis of the data. The significance level was set at $p$-value $\leq 0.05$. The normality distribution of continuous variable was evaluated by the Kolmogorov-Smirnov test. Two-way ANOVA was performed to compare the mean volume of voids in the apical third of the root canal according to two parameters: Type of sealer and taper. This analysis was followed by univariate analyses (one-way ANOVA and paired t-test) and Bonferroni multiple comparisons. One-sample t-tests were conducted to compare each mean void's proportion with the theoretical value 0 , which supposes the absence of voids.

\section{RESULTS}

\section{Comparison between Sealers}

For the $4 \%$ taper, the mean volume void in the apical third of the canal was significantly higher with NB sealer (p-value $<0.001)$. No significant difference was found between $\mathrm{AH}$ and TF ( $\mathrm{p}$-value $=1.000$ ).

For the $6 \%$ taper, the mean void volume in the apical third of the canal was significantly higher with NB ( $p$-value $<0.05)$. No significant difference was found between $\mathrm{AH}$ and TF $(\mathrm{p}$-value $=1.000)($ Table 1$)$.

\section{Comparison between Tapers}

This study did not show a statistically significant difference between the 4 and $6 \%$ taper for $\mathrm{AH}$ ( $\mathrm{p}$-value $=0.952$ ) and TF ( $p$-value $=0.390)$. On the contrary, the proportion of voids for the NB group was significantly higher at $4 \%$ compared with the $6 \%$ taper (p-value $<0.001$ ) (Table 1).

This study showed that the proportion of voids in each group was not significantly different from the theoretical value 0 ( $\mathrm{p}$-value $<0.05$ ). Therefore, the void was significantly present at the apical part of the roots regardless sealer and canal taper (Tables 1 and 2). 


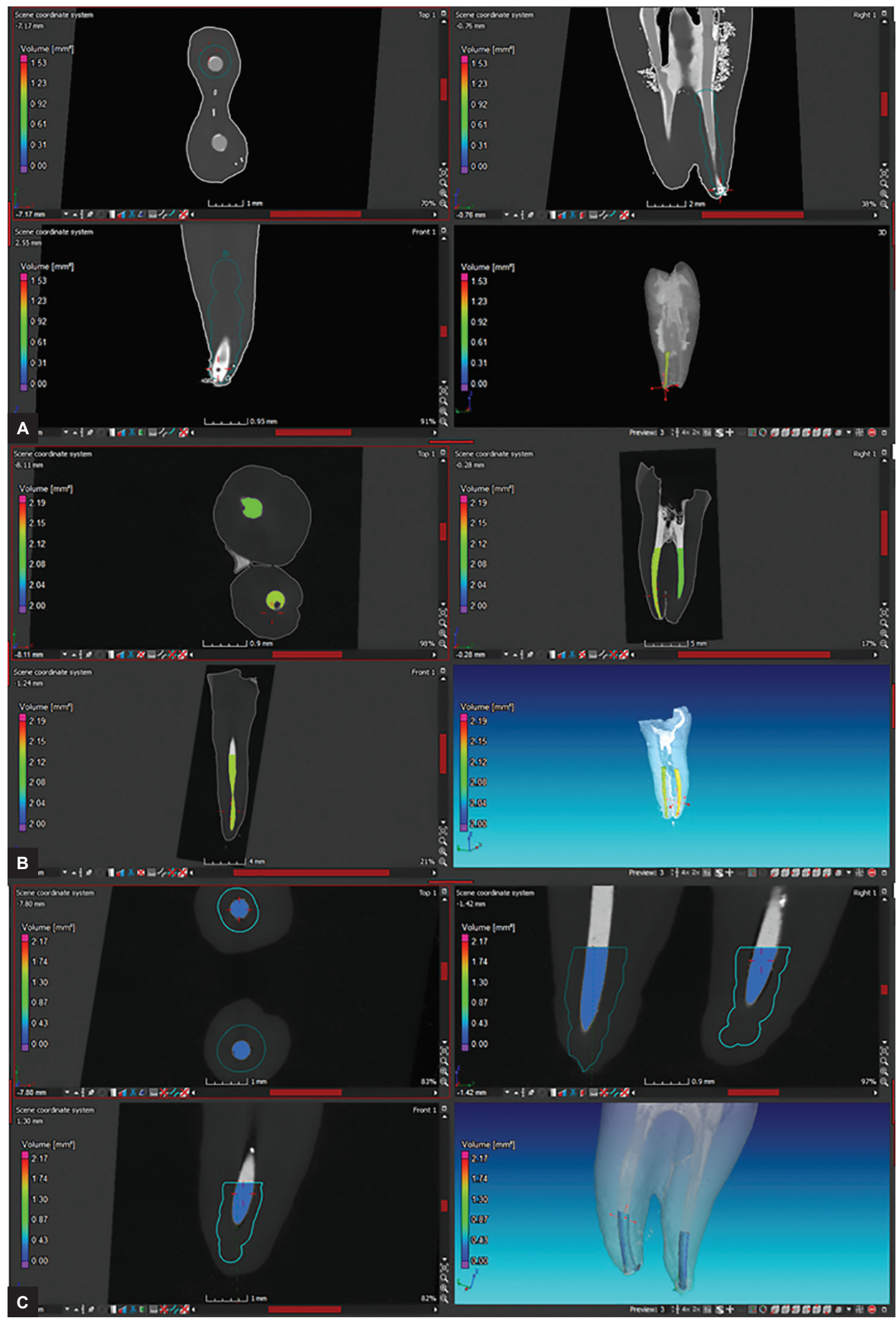

Figs 1A to C: Micro-CT analysis and void calculation on the root canals of maxillary premolars. (A) Void calculation in root canals shaped at 0.3 to 0.04 and filled in a single-cone technique using $\mathrm{AH}$. (B) Void calculation in root canals shaped at 0.3 to 0.04 and filled in a single-cone technique using TF. (C) Void calculation in root canals shaped at 0.3 to 0.04 and filled in a single-cone technique using the NB sealer (in color) 

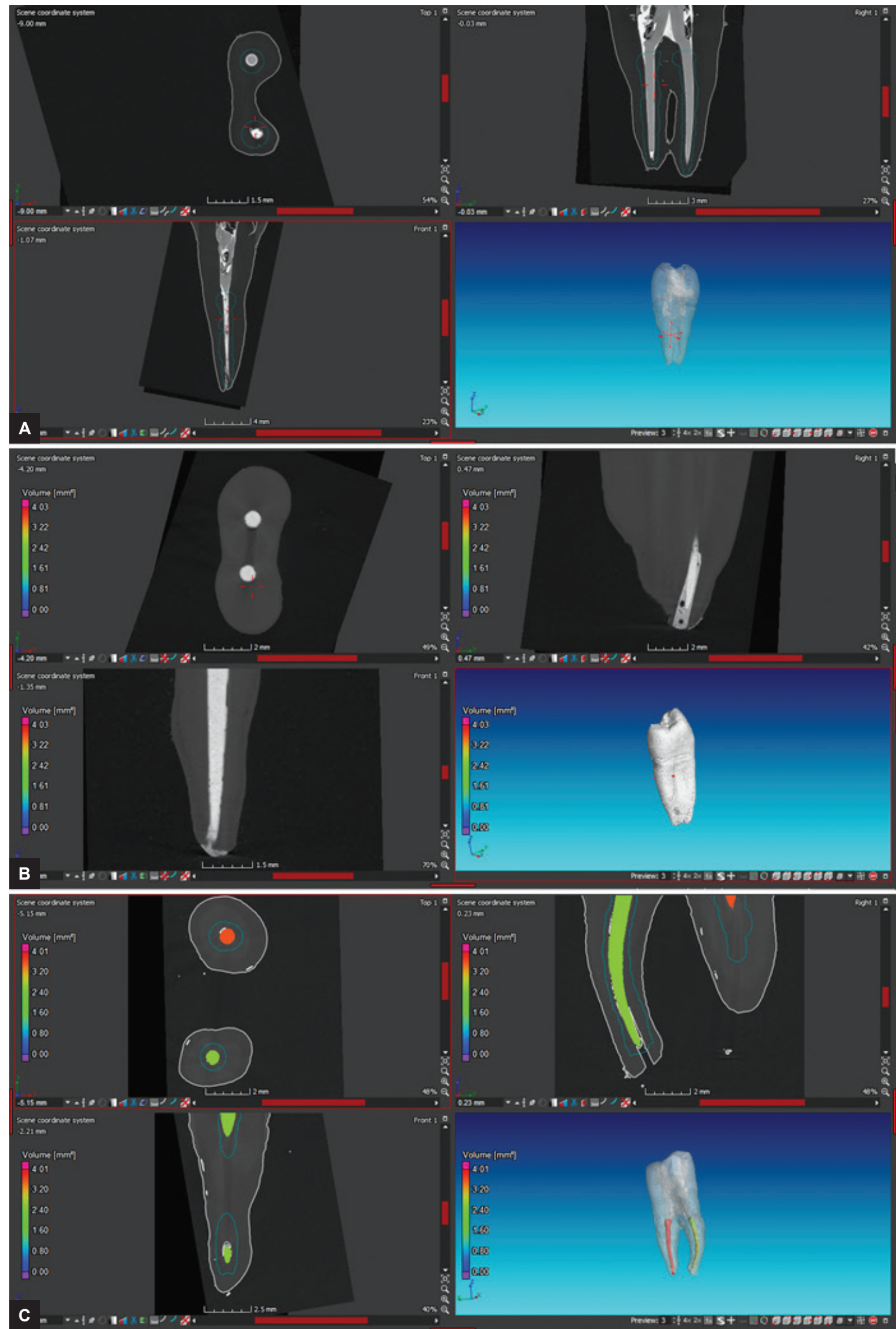

Figs 2A to C: Micro-CT analysis and void calculation on the root canals of maxillary premolars. (A) Void calculation in root canals shaped at 0.3 to 0.06 and filled in a single-cone technique using $\mathrm{AH}$. (B) Void calculation in root canals shaped at 0.3 to 0.06 and filled in a single-cone technique using the NB sealer. (C) Void calculation in root canals shaped at 0.3 to 0.06 and filled in a single-cone technique using TF (in color) 
Table 1: Mean and standard deviation values of voids in the apical third of all groups (ratio)

\begin{tabular}{|c|c|c|c|c|}
\hline Taper (\%) & Groups & $\begin{array}{l}\text { Number of } \\
\text { tooth }\end{array}$ & Mean & $\begin{array}{l}\text { Standard } \\
\text { deviation }\end{array}$ \\
\hline 4 & $\mathrm{AH}$ & 6 & 0.0354 & 0.0354 \\
\hline 4 & TF & 6 & 0.0370 & 0.0245 \\
\hline 4 & BC tested & 6 & 0.2852 & 0.0916 \\
\hline 6 & $\mathrm{AH}$ & 6 & 0.0447 & 0.0348 \\
\hline 6 & $\mathrm{TF}$ & 6 & 0.0588 & 0.0150 \\
\hline 6 & BC tested ${ }^{\circledR}$ & 6 & 0.1007 & 0.0267 \\
\hline
\end{tabular}

p-value <0.001: NB4 and the other groups; $p$-value $>0.05$ : No statistical difference between AH4, TF4, AH6, and TF6

Table 2: Mean and standard deviation values of voids of the three types of sealers evaluated (ratio)

\begin{tabular}{lll}
\hline Groups & Mean & Standard deviation \\
\hline $\mathrm{AH}$ & 0.045 & 0.033 \\
$\mathrm{TF}$ & 0.048 & 0.022 \\
Novel BC sealer & 0.193 & 0.012 \\
\hline
\end{tabular}

\section{DISCUSSION}

Preventing microorganism percolation is the major purpose of endodontic therapy. ${ }^{1}$ Filling hermetically the root canal system is a process that has been subject to various modifications from solid material (silver cones) to gutta-percha used in conjunction with sealers. ${ }^{16,17}$ Schilder ${ }^{1}$ introduced warm vertical compaction with proved capacity to fill root canal irregularities and better three-dimensional filled volume of gutta-percha and sealer. ${ }^{1,16-18}$ Since 1970, BCs have been used in dental research. ${ }^{8-10}$ They were recently used in endodontics due to their biocompatibility, chemical stability, and antibacterial action $(\mathrm{pH}>12.8)$. These sealers are used with "glassionomer-coated gutta-percha," in a single-cone filling technique. ${ }^{8,19}$ By creating a hydroxyapatite layer between gutta-percha cone and dentinal walls, ${ }^{8-10} \mathrm{BC}$ sealers are very promising compared with traditional ones. ${ }^{9,11}$ Tissue preservation is applied in order to prevent failure due to treated teeth fracture. ${ }^{20,21}$ Moreover, it reduces errors during root canal shaping, thus increasing success rate. ${ }^{22}$ While the concept of large apical diameters have literature credibility regarding bacterial elimination and irrigant penetration, a final taper $<6 \%$ and an apical diameter ranging between 0.2 and $0.4 \mathrm{~mm}$ are criteria for conservative preparations. ${ }^{5,6,22}$ Therefore, Schilder's vertical compaction being impossible to achieve in small tapered preparations, single-cone technique is recommended. ${ }^{23}$ For this, $\mathrm{BC}$ sealers may give better promising results. This study combines both dentinal preservation and the singlecone filling with two $\mathrm{BC}$ sealers in comparison to a conventional resin sealer. Maxillary premolars with two separate roots were selected. Their apical curvature and thin roots canals are the indication for minimal preparations. ${ }^{24,25}$ The
iRace (FKG Dentaire, Switzerland) instrumental sequence choice for all the groups was based on the constant apical taper of the R3 and its characteristics that corresponds to the conservative criteria. ${ }^{5,22}$ For disinfection, $10 \mathrm{~mL}$ of sodium hypochlorite and 17\% EDTA solution $(\mathrm{pH}=7.7)$ were used. The combination of $\mathrm{NaOCl}$ and EDTA removes the smear layer, permitting a better tubular penetration for the $\mathrm{AH}$, thus reducing voids volume. ${ }^{26,27}$ Studies proved that minimally treated root canals are less apically disinfected compared with enlarged ones. On the opposite, they contain pulpal remnants, bacteria that are responsible for postoperative disease. ${ }^{28}$ The EDTA solution in addition to sodium hypochlorite affected better the $\mathrm{AH}$ tubular penetration than the $\mathrm{BC}$ sealer. ${ }^{29}$ For Brunson et al, ${ }^{30} 8 \%$ tapered root canals were better disinfected than $4 \%$ for the same apical diameter. An older study of Khademi et al ${ }^{31}$ showed that bigger apical diameters $(0.35 \mathrm{~mm})$ result in a better apical third disinfection. Huang et $\mathrm{al}^{32}$ proved that an apical diameter of 0.4 is better than an apical diameter of 0.2 . Pasqualini ${ }^{33}$ found that the conservative concept of treatment is responsible for a less efficacious disinfection. The aim of our study was to compare the volume of apical voids after root canal obturation: Only external and combined voids between canal walls and gutta-percha were calculated: Their presence is significant to leakage. ${ }^{34}$ In vitro methods are unable to reproduce the clinical reality (electrochemical technique, dye penetration, etc.). Cone beam CT imaging improved managing artifacts, and is a noninvasive technique with comparable values to histological examination. Micro-CT is proved to be the best reliable technique nowadays, differentiating guttapercha, sealer, and voids. The superimposition of two scans has highest credibility. ${ }^{35,36}$ None of the subgroups was gap-free. This finding was consistent with other studies. ${ }^{37}$ While the mean value of voids in the apical third ranged between 3 and $28 \%$ in our study (Table 1), other researches proved that thermo-plasticized gutta-percha techniques analyzed on micro-CT showed remarkably less voids, achieving better filling of the anatomic irregularities. ${ }^{38,39}$ However, a recent study by Jeong et al ${ }^{40}$ resulted in a sealer penetration into dentinal tubules independently from the obturation technique. No statistical difference between 4 and $6 \%$ between $\mathrm{AH}$ and TF was observed in this study. The resin-based sealers shrink during the setting phase, which leads to gap and void formation..$^{39,41}$ Moreover, TF sealer creates a hydroxyapatite layer with dentinal walls. These findings were consistent with previous studies. ${ }^{39,41}$ In addition, the $4 \%$ taper showed significantly more voids compared with the $6 \%$ taper in the NB sealer group. The null hypothesis was rejected. Some other studies proved that enlarging the root canal taper increases the disinfectious action, improves sealing ability, and results in less voids. ${ }^{29,37,39,42}$ The TF and AH groups 
at 4 and $6 \%$ gave satisfactory results in the apical third when the fitted cone is well adapted to taper. For the NB sealer, $6 \%$ tapered preparations resulted in better fillings. This is probably due to the large diameter of particles of this sealer and its hard application in the thin root canal preparations.

Sealer's choice does not have a significant influence on apical adaptability of root canal obturation. However, the final taper of preparation is critical in sealing ability of obturating materials. The preliminary findings of the present study must be confirmed by further investigations that also evaluate other clinically improved properties of the new BC tested sealer.

\section{REFERENCES}

1. Schilder H. Filling root canals in three dimensions. Dent Clin North Am 1967 Nov;723-744.

2. Emery O. Leakage evaluation of the root canal fillings: a literature review. Rev Odont Stomat 2002 Nov;31:279-297.

3. Reeh ES, Messer HH, Douglas WH, Reduction in tooth stiffness as a result of endodontic and restorative procedures. J Endod 1989 Nov;15(11):512-516.

4. Tang $\mathrm{W}, \mathrm{Wu}$ Y, Smales RJ. Identifying and reducing risks for potential fractures in endodontically treated teeth. J Endod 2010 Apr;36(4):609-617.

5. Clark D, Khademi J, Herbranson E. Fracture resistant endodontic and restorative preparations. Dent Today 2013 Feb;32(2):118, 120-123.

6. Clark D, Khademi J, Herbranson E. The new science of strong endo teeth. Dent Today 2013 Apr;32:112, 114, 116-117.

7. Chen I, Karabucak B, Wang C, Wang HG, Koyama E, Kohli MR, Nah HD, Kim S. Healing after root-end microsurgery by using mineral trioxide aggregate and a new calcium silicate-based bioceramic material as root-end filling materials in dogs. J Endod 2015 Mar;41(3):389-399.

8. Best SM, Porter AE, Thian ES, Huang J. Bioceramics: past, present and for the future. J Eur Ceram Soc 2008 Dec;28(7): 1319-1327.

9. Prasannan R, Pillai R, Varghese NO, U-Nu S. Bioceramic sealers-game changer in endodontic obturation. JCAESOK 2012 Apr;2(1):42-44.

10. Koch K, Brave D, Nasseh AA. A review of the bioceramic technology in endodontics. CE Article 2014 Apr;4:6-12.

11. Koch K, Brave D. Bioceramic technology—the game changer in endodontics. Endod Pract 2009 Apr;12:13-17.

12. Hess D, Solomon E, Spears R, He J. Retreatability of a bioceramic root canal sealing material. J Endod 2011 Nov;37(11): 1547-1549.

13. Chakar S, Changotade S, Osta N, Khalil I. Cytotoxic evaluation of a new ceramic-based root canal sealer on human fibroblasts. Eur J Dent 2017 Apr-Jun;11(2):141-148.

14. Chen CC, Ho CC, David Chen CH, Ding SJ. Physicochemical properties of calcium silicate cements for endodontic treatment. J Endod 2009 Sep;35(9):1288-1291.

15. Khalil I, Naaman A, Camilleri J. Properties of tricalcium silicate sealers. J Endod 2016 Oct;42(10):1529-1535.

16. Robberetch L, Colard T, Claisse-Crinquette A. Qualitative evaluation of two endodontic obturation techniques: tapered single-cone method versus warm vertical condensation and injection system: an in vitro study. J Oral Sci 2012 Mar;54(1):99-104.

17. Ng YL, Mann V, Rahbaran S, Lewsey J, Gulabivala K. Outcome of primary root canal treatment: systematic review of the literature. Int Endod J 2008 Jan;41(1):6-31.

18. Ordinola-Zapata R, Bramante CM, Graeff MS, del Carpio Perochena A, Vivan RR, Camargo EJ, Garcia RB, Bernardineli N, Gutmann JL, de Moraes IG. Depth and penetration of endodontic sealers into dentinal tubules after root canal obturation using a lateral compaction technique: a confocal laser scanning microscopy study. Oral Surg Oral Med Oral Pathol Oral Radiol Endod 2009 Sep;108(3):450-457.

19. Nagas E, Uyanik MO, Eymirli A, Cehreli ZC, Vallittu PK, Lassila LV, Durmaz V. Dentin moisture conditions affect the adhesion of root canal sealers. J Endod 2012 Feb;38(2): 240-244.

20. Ericson D. The concept of minimally invasive dentistry. Dent Update 2007 Jan-Feb;34(1):9-10, 12-14, 17-18.

21. Murdoch-Kinch CA, McLean ME. Minimally invasive dentistry. J Am Dent Assoc 2003 Jan;134:87-95.

22. Clark D, Khademi J. Modern molar endodontic access and directed dentin conservation. Dent Clin North Am 2010 Apr;54(2):249-273.

23. FKG Catalogue/TotalFill ${ }^{\circledR}$ —Swiss Endo.

24. Vertucci, FJ.; Haddix, J. Tooth morphology and access cavity preparation. In: Cohen S, Hargreaves KM, editors. Cohen's pathways of the pulp. Chapter 7. 10th ed. St. Louis (MO): Mosby Elsevier; 2011. pp. 153-239.

25. Frater M, Forster A, JantyikA, Braunitzer G, Nagy K, GrandiniS. In vitro fracture resistance of premolar teeth restored with fibre-reinforced composite posts using a single or multi-post technique. Aust Endod J 2016 Apr;43(1):16-22.

26. Ahmaduddin AS, Bolla N, Raj S, Mandava P, Nayak S. Effect of final irrigating solution on smear layer removal and penetrability of the root canal sealer. J Conserv Dent 2014 Jan-Feb;17(1):40-44.

27. Sonu KR, Girish TN, Ponnappa KC, Kishan KV, Thameem PK. Comparative evaluation of dentinal penetration of three different endodontic sealers with and without smear layer removal-scanning electron microscopic study. Saudi Endod J 2016 Jan;6(1):16-20.

28. Ruddle CJ. Focus on: minimally invasive endodontics. Dent Today 2014 Apr;33(4):14.

29. Ozkocak I, Sonat B. Evaluation of effects on the adhesion of various root canal sealers after Er:YAG Laser and irrigants are used on the dentin surface. J Endod 2015 Aug;41(8): 1331-1336.

30. Brunson M, Heilborn C, Johnson J, Cohenca N. Effect of apical preparation size and preparation taper on irrigant volume delivered by using negative pressure irrigation system. J Endod 2010 Apr;36(4):721-724.

31. Khademi A, Yazdizadeh M, Feizianfard M. Determination if the minimum instrumentation size for penetration of irrigants to the apical third of root canal systems. J Endod 2006 May;32(5):417-420.

32. Huang TY, Gulabivala K, Ng YL. A biomolecular film ex-vivo model to evaluate the influence of canal dimensions and irrigant variables on the efficacy of irrigation. Int Endod J 2008 Jan;41(1):60-71.

33. Pasqualini D. Minimally invasive endodontics: a fancy trend or a clear road for the future? Int J Oral Dent Health 2015 Feb;1:1. 
34. Sauders WP, Saunders EM. Coronal leakage as a cause of failure in root-canal therapy: a review. Endod Dent Traumatol 1994 Jun;10(3):105-108.

35. Swain MV, Xue J. State of the art of micro-CT applications in dental research. Int J Oral Sci 2009 Dec;1(4):177-188.

36. Jung M, Lommel D, Klimek J. The imaging of root canal obturation using micro-CT. Int Endod J 2005 Sep;38(9):617-626.

37. Pereira AC, Nishiyama CK, de Castro Pinto L, Singlecone obturation technique: a literature review. RSBO 2012 Oct-Dec;9(4):442-447.

38. Zogheib C, Naaman A, Sigurdsson A, Medioni E, Bourbouze G, Arbab-Chirani R. Comparative micro-computed tomographic evaluation of two carrier-based obturation system. Clin Oral Investig 2013 Nov;17(8):1879-1883.
39. Zogheib C, Hanna M, Pasqualini D, Naaman A. Quantitative volumetric analysis of cross-linked gutta-percha obturators. Ann Stomatol (Roma) 2016 Jan;7(3):46-51.

40. Jeong JW, DeGraft-Johnson A, Dorn SO, Di Fiore PM, Dentinal tubule penetration of a calcium silicate-based root canal sealer with different obturation methods. J Endod 2017 Apr;43(4):633-637.

41. McMichen FR, Pearson G, Rahbaran S, Gulabivala K. A comparative study of selected physical properties of five root canal sealers. Int Endod J 2003 Sep;36(9):629-635.

42. Garrido AD, Lia RC, Franc SC, da Silva JF, Astofil-Filho S, Sousa-Neto MD. Laboratory evaluation of the physicochemical properties of a new root canal sealer based on Copaifera multijuga oil-resin. Int Endod J 2010 Apr;43(4):283-291. 